\title{
La calidad total en la Administración local. Fundamentos y orientaciones básicas
}

\author{
Valentín Merino Estrada \\ Secretario General del Ayuntamiento de Valladolid
}

SUMARIO: I. INTRODUCCIÓN. II. CALIDAD TOTAL EN LAS ADMINISTRACIONES PÚBLICAS. 1. Evolución del concepto de calidad en las organizaciones. 2. La excelencia en la gestión. 3. Administración pública y calidad: la legitimación como impulso. 4. Gobiernos, legitimidad y calidad. III. LA ADMINISTRACIÓN LOCAL ANTE LA CALIDAD. 1. El factor complejidad. 2. Proximidad y subsidiariedad. 3. Liderazgo fuerte. 4. Gobiernos locales y legitimidad «por calidad». IV. ORIENTACIONES BÁSICAS PARA UNA GESTIÓN LOCAL DE CALIDAD. V. A MODO DE CONCLUSIONES.

\section{INTRODUCCIÓN}

Los principios de la gestión de calidad y de la calidad total constituyen hoy día un modelo de referencia plenamente asumido por el conjunto de las Administraciones Públicas en España y en la U.E. Los gobiernos formulan declaraciones y aprueban Planes de modernización, de calidad o de mejora de los servicios. Las organizaciones administrativas aplican técnicas y herramientas de calidad adaptadas con mayor o menor fortuna del sector empresarial e incluso algunas construyen modelos propios.

La gestión de calidad se presenta no sólo como una filosofía de mejora sino también como una forma distinta de gobernar, más atenta a las expectativas de los ciudadanos, más participativa y democrática.

En este proceso relativamente generalizado de aplicación de la gestión de calidad, los grandes municipios han sido pioneros, y en general la Administración Local es la que presenta prácticas más exitosas y mejores resultados. Basta analizar el Banco de Datos de la F.E.M.P. sobre prácticas de modernización y calidad, para avalar con claridad esta afirmación.

Pero, además, entendida la calidad no como un conjunto de técnicas, sino como proceso de mejora integral de los rendimientos, el diferencial a favor de las Administraciones Locales es aún mayor. Los municipios, con técnicas conocidas y explícitas de gestión de calidad o sin ellas, son la Administración que ofrece mayor eficiencia y mejores rendimientos. En los últimos años dos factores entrelazados han contribuido poderosamen- 
te a un incremento de este fenómeno: la escasez de recursos en las haciendas locales y la fuerte presión vecinal, en un contexto de máxima proximidad.

En este trabajo presentamos, en primer lugar, los rasgos fundamentales de la calidad total como paradigma actual de gestión y su aplicación a las Administraciones Públicas. A continuación analizamos las características distintivas más notables que presentan las Administraciones Locales como organizaciones, en relación a los requerimientos de la calidad, tratando de encontrar explicaciones y el fundamento del mayor éxito que están teniendo en el proceso de desarrollo. Finalmente exponemos un marco conceptual y los lineamientos básicos de lo que podemos considerar como modelo de gestión excelente en el ámbito municipal.

\section{CALIDAD TOTAL EN LAS ADMINISTRACIONES PÚBLICAS}

\section{Evolución del concepto de calidad en las organizaciones}

Trabajar con calidad significa satisfacer las necesidades y aspiraciones del cliente con amabilidad, prontitud y eficacia, a costes moderados. La calidad tiene un objetivo: responder a las expectativas del cliente, y una forma de conseguirlo: hacer las cosas bien, utilizando de forma racional los medios disponibles. Así planteada, la calidad no es un objetivo, sino un proceso de mejora continua.

Es el paradigma actual de Calidad Total:

- Satisfacer los requerimientos y las expectativas de los clientes y usuarios del servicio.

- Buscar la mejora continua y a largo plazo en los procesos y actividades de la organización.

- Conseguir la participación de todos los trabajadores en la mejora de la calidad.

En definición que nos proporciona el Federal Quality Institute (U.S.A.). Un concepto amplio, una filosofía transformadora de las organizaciones.

Pero las cosas no se han visto siempre así. El concepto de calidad total es fruto de un proceso evolutivo del sentido de la calidad en las organizaciones. 
A principios del pasado siglo, los primeros enfoques de calidad surgen relacionados con el ahorro o reducción de costes. Las compañías industriales son conscientes de que una buena parte de sus costes se deben al rechazo de productos deficientes, a la compensación de clientes insatisfechos, etc., y deciden intervenir controlando, primero los productos y luego los procesos. Es la etapa del «control de calidad». En la década de los treinta, la calidad se entiende relacionada con especificaciones técnicas del producto, se aplica en entornos industriales de producción masiva y se apoya con elementos estadísticos complejos englobados en el concepto de Statistic Process Control, SPC. En el marco de los paradigmas taylorianos imperantes en ese momento, encaminados a conseguir la máxima eficacia productiva, se presta muy poca atención a las necesidades ó expectativas del consumidor.

Tras la idea de control, se impondrá la del aseguramiento. Se conoce como aseguramiento de calidad, un sistema organizado y documentado de procedimientos que dentro de ciertos límites nos permiten esperar que el producto, servicio o prestación resultante va a satisfacer los requisitos de calidad. Se analizan los procedimientos y se documentan en un Manual de Calidad especificaciones y registros. Si se siguen adecuadamente, se establece la presunción de homogeneidad, fiabilidad y por ende calidad. Un extraordinario papel en la implantación de estos conceptos tuvo la International Organization for Standardization, fundada en Londres en 1947, encargada de desarrollar y homogeneizar la normativa convencional a cumplir por los diferentes productos. Sus trabajos desembocarían muchos años después en la publicación de las famosas normas ISO. Es importante destacar que los sistemas de aseguramiento no sustituyen al control, sino que lo integran y asimilan en una concepción más amplia.

En los primeros años tras la guerra mundial, se produce la introducción de los conceptos de calidad en Japón, de la mano de los profesores y expertos americanos Deming y Juran. Los japoneses, estimulados ante la carencia de recursos de sus país y por determinadas peculiaridades de su cultura, hicieron importantes aportaciones a las ideas de calidad: prevención, adhesión corporativa y espíritu de mejora permanente (el KAIZEN). Los japoneses fueron los primeros en romper la tradicional división entre los que piensan (la Alta Dirección) y los que ejecutan, para involucrar a todos en la tarea de lograr los mejores resultados organizacionales. En los desarrollos observados en Japón encontramos bastantes elementos y principios de lo que luego sería conocida como «calidad total». Pero el modelo japonés tuvo un desarrollo amplio en el campo de la fabricación industrial, teniendo en cambio escasa repercusión en el sector servicios. 
A partir de mediados de los ochenta, con el desarrollo de lo que se conoce como sociedad abierta, la competencia se acelera y no conoce fronteras. El consumidor informado se torna sumamente exigente. Las organizaciones tienen que «aprender» a moverse en un medio incierto. Para alcanzar el éxito, incluso a veces para sobrevivir, tiene que anticiparse, conocer bien las expectativas del consumidor y poner en tensión todos los recursos, principalmente los intangibles, el capital intelectual. En este contexto surgen las ideas clave que van a conformar el nuevo paradigma: la satisfacción del cliente, como meta y motor de la organización y la participación de todos en el logro de los objetivos.

Las organizaciones son entendidas como conjunto de procesos orientados al cliente. El concepto de cliente va más allá de lo comercial. Toda unidad organizativa tiene cliente: el destinatario de su actividad (Noción cliente externo-interno). La referencia del cliente está siempre presente en cada etapa del proceso. Cualquier proceso es susceptible de análisis, medición y mejora. El objetivo es la mejora continua de todos los procesos y actividades de la empresa. La mejora sólo se puede lograr poniendo en juego todas las capacidades, mediante la participación de todos. La racionalización deja de ser el factor determinante del éxito. En un mundo de cambio acelerado, la capacidad de adaptación, el aprendizaje, en suma la innovación pasa a ser, como acertadamente expresó CROZIER, el valor supremo ${ }^{1}$.

Otro cambio importante en esta etapa lo constituye la aplicación de modelos de calidad en las organizaciones prestadoras de servicios, coincidiendo con el auge del sector, que ha pasado a ser predominante en el conjunto de la economía. Tradicionalmente el término calidad se vinculaba a características o especificaciones de producto. La aplicación del concepto a los servicios provoca una profunda revisión, pasando a considerarse como proceso de gestión integral de las actividades de la empresa, para satisfacer con eficacia las expectativas del cliente. En el plano teórico surgen importantes aportaciones sobre las características, dimensiones y atributos de la calidad en los servicios e incluso se formulan modelos de «Calidad Total en Servicios» ${ }^{2}$.

Así llegamos al concepto actual de Calidad Total. Un concepto amplio, abierto y flexible, de aplicación general a todo tipo de organizaciones.

\footnotetext{
1 «Tout d'abord, dans un système de producción en evolutión accéléreé, la capacité d'innover devient la qualité première par rapport a la capacité de rationaliser». M. Crozier, L' entreprise à l'ecoute. París, 1991.

${ }^{2}$ L. Berry; A. Parasuraman y V. A. Zeithaml: Calidad Total en la Gestión de Servicios. Madrid, 1993.
} 
Una filosofía transformadora: estrategia de dirección orientada al cliente y basada en el compromiso.

\section{La excelencia en la gestión}

Así como el aseguramiento no sustituyó al control sino que lo integró en una nueva dimensión, las ideas de mejora continua y de calidad total no sustituyen al control de costes, a la normalización ni a la racionalidad de los procesos, sino que los integran y sitúan en un nuevo contexto relacional más abierto, dominado por la creatividad y la innovación. El concepto de calidad total se ha conformado no por sustitución, sino por integración. De ahí su carácter comprensivo y polivalente. Puede ser aplicado a cualquier organización, con la necesaria adaptación. Pero los principios y fundamentos básicos son aplicables «a la organización» sin más calificativos.

Se dice que la Calidad Total es un estado, una forma de dirección, una estrategia; incluso algunos autores hablan de una «opción de vida». Pero en todo caso es gestión: una estrategia o una filosofía de gestión. En la actualidad, al tiempo que asistimos a una convergencia entre las distintas «técnicas» o modelos ${ }^{3}$, se refuerza la idea de Calidad Total como sistema de gestión. La calidad no puede recorrer caminos paralelos. Sin gestión no hay calidad. La calidad no es sino la mejora constante, medible y constatable de una gestión. Para reforzar esta idea, algunos prefieren sustituir el Total Quality Management (TQM) por la Excelencia en la Gestión. La denominación no es lo importante. La idea-fuerza es la identificación de la Calidad o la Excelencia con la mejora de los resultados organizacionales en el sentido más amplio:

- Mejora de la calidad del producto o servicio

- Mejora de la satisfacción del cliente

- Mejora de la satisfacción de los trabajadores (participación-innovación)

- Mejora de incremento de la productividad

- Mejora de posiciones en la competitividad-legitimidad.

\footnotetext{
${ }^{3}$ Las nuevas ISO 9000/2000 plantean el cambio del aseguramiento a un modelo de gestión integral, reforzando conceptos clave: «satisfacción del cliente», «mejora continua»... El Modelo de Excelencia E.F.Q.M. está en crisis y revisión. El nuevo modelo introduce factores de objetividad, mayor concreción y garantías. Las organizaciones apuestan por la mixtura y por modelos «propios».
} 


\section{Administración Pública y calidad: la legitimación como impulso}

Los principios y las prácticas de la Gestión de Calidad Total son plenamente aplicables a y en la Administración Pública. Pero no como se ha dicho porque al ser aplicables al sector servicios y siendo la Administración Pública una «gigantesca máquina de prestar servicios», hablar de calidad en los servicios es hablar de calidad en las administraciones públicas o viceversa. Ésta es una visión parcial y reduccionista que no compartimos. En primer lugar porque las tareas de la Administración Pública son más amplias, complejas y de naturaleza distinta, siendo las prestacionales sólo una parte, aunque más visible y mayoritaria en un momento histórico dado. Identificar calidad en la Administración con calidad en los servicios públicos dejaría fuera un conjunto de actividades relevantes que forman parte de la función central que aquella desempeña en el sistema social. En segundo lugar porque la verdadera razón de fondo, el fundamento de la aplicación no está ahí, como luego veremos.

La Administración Pública es una organización; articulación de capacidades y recursos para el logro de un fin. Esta sencilla y elemental afirmación tiene unas consecuencias lógicas importantes: como tal organización tiene principios, elementos estructurales y reglas de funcionamiento que son comunes al conjunto de organizaciones sociales, tanto públicas como privadas. Asimismo, como organización tiene que obtener unos resultados, unos rendimientos y para ello utilizar procedimientos y sistemas de gestión.

Como organización específica, la Administración Pública se singulariza en atención a la función central que desempeña en la sociedad global ${ }^{4}$. La Administración Pública es un complejo orgánico, que bajo la dirección del poder político desarrolla una función central de coordinación y dirección de la sociedad global. Para desarrollar esta función central, la Administración

\footnotetext{
${ }^{4}$ Renate MAYNTZ ha descrito con gran claridad el desarrollo de la Administración Pública y la función central que ésta desempeña en la sociedad: «el desarrollo de la Administración Pública es la expresión de una transformación fundamental en la estructura del sistema social global, que se conoce como proceso de diferenciación: división progresiva del trabajo y formación de subsistemas funcionalmente especializados (sistema económico, educativo, científico, religioso ...). La formación de subsistemas implica un cierto grado de autonomía para éstos, que sin embargo va unida a una interdependencia más o menos marcada. Se hace necesaria funcionalmente la coordinación con reducción a la unidad, la orientación del conjunto social. Es ésta una función central que se asignará un núcleo organizativo diferenciado: el subsistema político-administrativo. En éste la Administración aparece como órgano ejecutor de las políticas, con cierta singularidad propia. R. MaYnTZ, Sociología de la Administración Pública. Alianza Universidad. Madrid, 1985. Sobre el mismo tema ver S. M. LIPSET, El hombre político. Las bases sociales de la política. Tecnos. Madrid (1987). T. PARsons, El sistema social. Alianza Editorial. Madrid (1982).
} 
Pública desempñea múltiples tareas de naturaleza variada y contingente: de reglamentación, de aseguramiento, prestacionales, de liderazgo... Las tareas prestacionales, de contenido positivo, económico o técnico, actualmente predominantes, surgieron tardíamente en términos históricos. Mientras que las funciones reguladoras son consustanciales a la existencia misma del sistema político-administrativo («funciones de soberanía» del Estado nacional), las prestacionales fueron asumidas gradualmente por éste, hasta convertirse en masivas y omnipresentes. A lo largo del último siglo, hemos transitado desde una Administración Pública fundamentalmente ordenancista a otra prioritariamente dedicada a la prestación masiva de servicios. En consecuencia, la relación Administración-Ciudadano y la percepción que de la Administración Pública tiene la sociedad ha sufrido notables cambios. El ciudadano, usuario o receptor de servicios, ha pasado a percibirse a sí mismo como «cliente» y a exigir que la Administración actúe en consecuencia. El carácter instrumental, servicial, de la Administración Pública, es asumido explícitamente por la sociedad.

«La Administración Pública sirve con objetividad los intereses generales...» (art. 103 de la Constitución Española). La misma idea: «La Administración Pública está al servicio de los ciudadanos y ciudadanas...» (art. 141 de la Constitución de la R.B. de Venezuela). La función central se identifica con el servicio a la sociedad. La Administración Pública sirve a los ciudadanos en todas sus tareas o funciones, no sólo cuando realiza prestaciones. La justicia, la diplomacia, la policía, el fisco... aunque sirven al ciudadano, a la sociedad, no son servicios públicos. La Administración Pública es un ente instrumental, con clara orientación finalista. No tiene sentido en sí misma y sólo se legitima en la medida en que resuelve adecuadamente su función de servicio a la sociedad, en la medida en que resuelve «los problemas» sociales. Esto afecta a toda la Administración Pública, en las distintas facetas de su actividad y es inseparable del propio concepto, de su especificidad organizacional, aunque sólo recientemente sea percibido por la ciudadanía en general.

Si la competitividad es el motor que ha impulsado a las organizaciones industriales y más tarde de servicios a trabajar con Calidad, lo que impulsa a la Administración Pública es la búsqueda de legitimidad, el fortalecimiento de su legitimidad por rendimientos.

Rafael BAÑón y Ernesto CARRILlo distinguen dos fuentes de legitimación para la Administración Pública ${ }^{5}:$ «Sentadas estas conclusiones queda

${ }^{5}$ R. Bañón y E. CArrillo, «La legitimidad de la Administración Pública» en La Nueva Adminis-
tración Pública. Alianza Universidad Textos. Madrid, 1997. E. CARrillo, «Legitimidad y moder- 
el problema de indagar mediante qué formas puede obtener legitimidad la Administración. Desde un punto de vista analítico cabe distinguir dos fuentes de legitimación:

- La legitimidad institucional, que deriva del ajuste del comportamiento de la Administración a un sistema de valores socialmente aceptados sobre cómo debe ser la Administración Pública en un Estado social y democrático de Derecho. Es decir, cómo se comporta la Administración, esto es, bajo qué sistema normativo se rige su comportamiento.

- La legitimidad por rendimientos que se obtiene produciendo políticas, bienes y servicios públicos que responden a criterios de evaluación de lo público socialmente aceptados. Esto es, qué resultados obtiene en el desempeño de sus funciones.

En otras palabras, la legitimidad institucional de la Administración y la legitimidad por rendimientos entroncan, respectivamente, con las dimensiones de legitimidad y eficacia del sistema político».

Cualquier organización necesita justificarse y la Administración no escapa a esta regla. La Administración Pública necesita legitimarse. Integrada como está en el sistema político-administrativo, recibe parte de su legitimidad del propio sistema: legitimidad institucional. Otra parte la obtiene en función de la generación de outputs o rendimientos en la solución de los problemas sociales. Es una legitimación de eficiencia. A su vez, esta última influye en la propia legitimidad global del sistema político y por ello tiene cada día más importancia.

Las necesidades de legitimación de la Administración se han multiplicado en la sociedad abierta. Por una parte, se cuestiona su capacidad para generar rendimientos que corrijan los fallos del mercado, así como su eficiencia en un contexto de crisis del Estado del bienestar y, por otra, se plantean alternativas de producción de servicios por organizaciones distintas, de tal forma que el sistema político pudiera cumplir funciones prescindiendo del aparato administrativo. En la sociedad actual, la tensión de la Administración Pública por legitimarse es evidente y constituye el motor central que empuja en el camino de la excelencia en la gestión.

nización de la Administración Pública» GAPP. n. ${ }^{\circ}$ 7-8, septiembre 1996 y abril 1997; ver también: J. Habermas, Problemas de legitimación en el capitalismo tardío. Amorrortu. Buenos Aires, 1995; R. Laufer y A. Burlaud, Dirección Pública, gestión y legitimidad. C. Estudios. INAP. Madrid, 1989. 
La Administración Pública accede a la Gestión de Calidad Total a impulsos de la necesaria legitimidad y no de la competencia. Por ello, la Calidad no puede ser una moda importada o adoptada del sector privado, ni la mera aplicación de modelos de calidad para servicios. Es algo mucho más profundo, relacionado con las necesidades de legitimación. Con elementos comunes, la Calidad es para la Administración Pública un camino propio, una dimensión esencial de su propio proceso de modernización.

A finales de los ochenta, se conoce como «modernización» de la Administración Pública un proceso de cambio, tendente a superar la falta de congruencia entre la sociedad-ambiente abierta, dinámica, exigente y la organización administrativa que seguía trabajando con principios, técnicas y modelos referenciales weberianos. Las formas y contenidos que adopta esta «modernización» son muy variados, pero existía un cierto consenso sobre los cuatro grandes vectores de intervención:

- Estrategias: definir metas y objetivos.

- Organización interna: estructuras más planas, dinamizadoras.

- Recursos Humanos: desarrollar el potencial de las personas.

- Relación con el ciudadano: receptividad.

La separación es evidentemente analítica ya que en el proceso interactúan los distintos vectores. Si uno debemos considerarle principal es el de las relaciones con el ciudadano: aumenta la satisfacción del ciudadano receptor de sus políticas públicas, ha de ser el principio orientador de la modernización administrativa. Esta aseveración nos conduce de forma inmediata a la Gestión de Calidad Total. En ella todo está en función del cliente. Una noción de «cliente» amplia y funcional: destinatario de la actividad sobre cuyas expectativas diseñamos los procesos. Para la Administración Pública, en todas sus funciones, en el «cliente» es el ciudadano al que sirve. Es «cliente» y es «accionista», es el referente único $\mathbf{y}_{\text {absoluto }}{ }^{6}$. La Calidad en la Administración Pública es una etapa más del proceso modernizador, un enfoque de la necesaria modernización. Trabajar en calidad es la base de la legitimidad propia y aporta legitimidad al sistema. Esto es lo fundamental. La Administración debe partir de su propia realidad organizacional, huir del mimetismo y la moda fácil; tener su propia orientación y construir sus propios modelos globales.

\footnotetext{
${ }^{6}$ A propósito de la falsa polémica ciudadano-cliente, ver S. RICHARDS, « El paradigma del cliente en la Gestión Pública». GAPP. n. ${ }^{\circ}$ 1, septiembre-diciembre 1994.
} 


\section{Gobiernos, legitimidad y calidad}

Trabajar con calidad no sólo reporta rendimientos y por ende legitimidad de eficiencia, sino que también contribuye a una forma de gobernar más democrática, en la medida en que fortalece la posición del ciudadano corriente. De esta forma aporta legitimidad general al sistema político.

La Administración Pública es un ente instrumental dirigido por el gobierno, núcleo decisional del sistema. Para el cumplimiento de sus fines, la Administración desarrolla «políticas públicas» que en lo esencial deciden los gobiernos (si bien en un marco plural de interacciones). Las políticas públicas (sociales, educativas, culturales...) son cauces de acción orientados a un fin. Responden a procesos interactivos en el que intervienen distintos actores, con distintos intereses en juego.

Los ciudadanos son a la vez referente fundamental para la determinación de las «políticas», elemento material del proceso interactivo y criterio determinante de la evaluación final. La opinión de los ciudadanos en la determinación de los objetivos, la participación en el proceso y su valoración de los resultados y efectos, son elementos clave, que redundan en la eficacia y la legitimidad de la Administración Pública. El ciudadano ha de ver resueltos sus problemas los que realmente considera «como suyos» y sentirse partícipe en la implementación de las soluciones.

Pero no podemos olvidar que la Administración está al servicio de una sociedad concreta, con determinados valores y creencias. Además, está inserta en el complejo sistema político-administrativo y dirigida por el poder político que emana de la sociedad. Las políticas son algo distinto del «juego de la política», entendido éste como proceso competitivo por el núcleo central del sistema. Sin embargo, no son totalmente separables, sino interdependientes.

El ciudadano otorga legitimidad al sistema político con su creencia de que resulta ser el mejor de los posibles. Esto tiene cierta sustantividad propia respecto a la solución eficiente de los problemas sociales. La legitimidad global del sistema y la legitimidad de eficiencia se complementan e interactúan. En ambas, la participación ciudadana es sumamente importante. El ciudadano ha de ser y sentirse participe tanto en el juego del poder como en el desarrollo de las políticas concretas. Por ello, como dice LindBLOM, en el mundo democrático las dos cuestiones más sobresalientes sobre la política gubernamental se centran en su efi- 
cacia en la solución de problemas y en el grado de respuesta del control popular ${ }^{7}$.

Pues bien, a pesar de todas las formulaciones enfáticas al respecto, en las sociedades democráticas modernas, el control ciudadano sobre el proceso y resultados de las políticas públicas es muy débil. La participación política, a través de los partidos y el voto, es un control poco eficaz desde el punto de vista de las «políticas públicas». El control democrático del voto es sustancial en cuanto al juego global de poder en el sistema político. Pero en relación a la Administración y sus «políticas» resulta un control muy débil por su naturaleza unidimensional, por la falta de identificación de las alternativas concretas, por las constantes alteraciones, ambigüedades programáticas, etc.

Por ello, quizás, los sistemas democráticos modernos y en eso la Constitución Española de 1978 resulta paradigmática, desarrollan y potencian, junto a la participación política, un entramado institucional de participación social. Pero este tipo de participación es, con frecuencia, monopolizada por grupos organizados de presión, auténticos núcleos de poder, reducidos y no legitimados por el voto, que «taponan» la participación del ciudadano corriente.

La Administración Pública, para ser eficiente, debe fortalecer la posición del ciudadano corriente en el proceso de formulación y desarrollo de las políticas públicas.

- Formulando Encuestas, para conocer la opinión, las demandas y valoraciones del ciudadano, que habrán de contar a la hora de priorizar la Agenda de los poderes públicos.

- Desarrollando amplia Información sobre las políticas y su desarrollo, con lo que se favorecerán las aportaciones ciudadanas, en un lógico proceso de retroalimentación.

- Diseñando y poniendo en práctica cauces concretos de participación en el desarrollo del proceso de gestión que siguen las políticas públicas.

- Fomentando la evaluación participativa de los efectos en los ciudadanos destinatarios y en la sociedad.

${ }^{7}$ Charles E. LindBlom, El proceso de elaboración de políticas públicas. Estudios. MAP. Madrid, 1991. 
Pues bien, trabajar con calidad; desarrollar sistemas de Calidad Total es la mejor forma de fortalecer la posición del ciudadano corriente en el proceso de formulación y desarrollo de las políticas públicas. La Calidad Total, con el ciudadano como eje y referente fundamental, integra es un sentido de globalidad casi todas las técnicas e instrumentos de participación del individuo en los procesos de gestión de las políticas públicas. Con ello, al tiempo que aporta legitimidad de rendimientos, confiere dimensión democrática a la acción de gobierno ${ }^{8}$, y por ende potencia la legitimidad global e institucional del sistema político-administrativo en su conjunto.

\section{LA ADMINISTRACIÓN LOCAL ANTE LA CALIDAD}

La caracterización de la Administración Local como tipo de la Administración Pública viene dada por el principio de autonomía local, que la configura y determina su inserción en el sistema político-administrativo sobre la base de tres elementos:

- El democrático: el gobierno de las Administraciones Locales corresponde directamente a los ciudadanos (Concejo Abierto) o a sus representantes elegidos (directamente en el caso de los municipios). Lo que pone de manifiesto la conexión del gobierno local con la participación ciudadana como derecho fundamental (art. 23 del Texto Constitucional).

- La personificación: los entes locales constituyen sistemas y ordenamientos de carácter parcial, pero completos en sí mismos, no jerarquizados en relación a otros gobiernos. Actúan bajo su propia responsabilidad.

- El corporativo: están llamadas a gestionar el universo de intereses de la comunidad respectiva.

Aparecen así los Entes Locales como un tipo de Administración que actúa democráticamente y bajo su propia responsabilidad gestionando el

\footnotetext{
${ }^{8}$ Quim BruguÉ, «La dimensión democrática de la Nueva Gestión Pública». GAPP n. ${ }^{\circ}$ 5-6. Enero-agosto, 1996; J. LóPEz CAMPS, «Gobernar es gestionar con Calidad». GAPP n. ${ }^{\circ}$. 11-12. Enero-agosto, 1998; J. Subirats, «Democracia, participación y eficiencia». GAPP n. ${ }^{\circ}$ 5-6. Enero-agosto, 1996.; A. Ramiro Sánchez, Demandas de calidad de la Administración Pública: un derecho de la ciudadanía. Dykinson. Madrid, 2002; M. Villoria Mendieta, La modernización de la Administración como instrumento al servicio de la democracia. Estudios. INAP, Madrid, 1996.
} 
conjunto de intereses de las colectividades más primarias del entramado social. Ésta es una caracterización tipológica. Y empleamos el plural porque en realidad la Administración Local no existe. Se trata de un tipo o más bien de una construcción normativa. En la realidad cada ente local es una organización en sí misma a la que resultan aplicables los elementos señalados. Más allá de éstos, de un «rol genérico» y de un bloque normativo común y artificialmente uniforme, existe una gran pluralidad, todo un cosmos organizativo, máxime teniendo en cuenta los niveles y la gran fragmentación existente en nuestro sistema.

En adelante nos referiremos fundamentalmente al Municipio por ser la Entidad Local básica y por su caracterización como cauce inmediato de participación ciudadana en los asuntos públicos. Esto le coloca, por lo antes expuesto, en directa relación con la filosofía y las estrategias de la Entidad Total. Más aún en las grandes ciudades, escenario en el que confluyen todas las fuentes de acción política y administrativa; sus diversos actores y una masa de ciudadanos especialmente crítica.

Analizamos, pues, las características más destacadas del Municipio como organización, desde la óptica de la Calidad Total antes expuesta para las Administraciones Públicas y de forma sintética nos referiremos a tres: la complejidad, la proximidad y el liderazgo fuerte.

\section{El factor complejidad}

La organización municipal tiene una extraordinaria complejidad en relación a su tamaño. Esta afirmación puede sorprender y por supuesto ser discutida por quienes no conozcan bien el microcosmos de lo municipal, y sin embargo nos parece una de las características más claras e influyentes. Evidentemente la complejidad y la simplicidad son términos siempre relativos. Además, la sociología de las organizaciones y las teorías sistémicas han ofrecido concepciones muy diversas sobre el término complejidad. Pero si tomamos la conocida fórmula de Ruggie, que hace muy comprensible el concepto, desde un cuadro analítico, sencillo, pero efectivo, y la aplicamos al Municipio veremos conclusiones muy claras:

$$
\mathrm{C}=\mathbf{f}[\mathbf{Q}, \mathrm{D}, \mathbf{R} \Delta(\mathbf{Q}, \mathrm{D}, \mathbf{R})]
$$

La complejidad de una organización está en función del número de sus componentes $(\mathrm{Q})$, del grado de diversificación entre ellos (D), del número 
e intensidad de sus relaciones $(\mathrm{R})$ y de la velocidad de cambio de todos estos factores 9 .

El término componentes se refiere tanto a estructuras como a funciones o medios de acción. El municipio que gestiona el universo de intereses de su comunidad desarrolla casi todas las funciones conocidas en el sistema e interviene relacionalmente en las demás. En la organización de los grandes municipios encontramos una gama amplísima de estructuras y formas de acción. La diversificación aún es mayor, pues en «un plano a escala», el microcosmos municipal reproduce toda la variedad del sistema. Se dan todo tipo de relaciones intra y extra. El factor «velocidad de cambio» es importantísimo en las grandes ciudades, escenario privilegiado de la innovación, en el que comienzan casi todos los cambios.

El problema que presenta la complejidad es la necesidad de controlarla o dominarla. En los municipios, se intentó en el pasado dominar la complejidad con una visión «micro», creando estructuras reducidas y supuestamente autónomas. En general se consiguió el efecto contrario: aumentar la complejidad y la dispersión. El dominio de la complejidad exige una visión amplia y anticipadora, estratégica, que se apoye en un sistema global e integral de gestión. La gestión de la complejidad organizadora «exige definir la acción racional, para identificar los medios para llevarla a cabo y para manejar y coordinar un gran número de variables interdependientes» ${ }^{10}$, lo que hoy resulta posible debido a los progresos de la tecnología intelectual.

El dominio de la complejidad requiere una política proyectiva, anticipatoria. La organización debe definir su misión, sus metas y grandes líneas de actuación. Para llevar a efecto esas estrategias y redefinirlas constantemente como exige el entorno, debe disponer de un sistema global e integral de gestión. En este sistema, tendrán cabida la variedad de técnicas apropiadas para la variedad de funciones y situaciones; las «visiones micro» en lo organizativo. Pero siempre insertas en una «visión macro», integradora.

La Gestión de Calidad Total aporta ese sistema integral, global y flexible, debiendo adaptarse en cada municipio, utilizando en cada situación las técnicas y herramientas más adecuadas.

\footnotetext{
${ }^{9}$ La fórmula fue utilizada ya en la década de los ochenta para el análisis político de la complejidad estatal. M. García-Pelayo, Las transformaciones del Estado contemporáneo. Alianza. Madrid, 1987.

${ }^{10}$ D. BeLl, El advenimiento de la sociedad post-industrial. Madrid, 1973, pp. 46 y ss.
} 


\section{Proximidad y subsidiariedad}

La Administración Municipal está siempre en contacto directo y personal cono los ciudadanos. Esto tiene implicaciones en el tipo de funciones que dentro del sistema se le atribuyen; en las condiciones y formas de desempeñar esas funciones y en la relación de intermediación entre los ciudadanos y otros gobiernos que en muchas ocasiones le corresponde desarrollar.

- La diferenciación de funciones entre los distintos niveles de gobierno-administración responde a una distribución competencial legalmente establecida. Los ciudadanos no acostumbran a conocerlo y acuden a la Administración más cercana y asequible. Al municipio le demandan soluciones en relación con las políticas públicas que más influyen de forma directa y cotidiana en su vida. Suelen ser servicios públicos con alta variación de la necesidad individual, de carácter frecuente, directo y localizados territorialmente. Pero no sólo servicios; esto afecta también a políticas reguladoras y de defensa del orden interno. Cuando un problema social afecta a personas y colectivos específicos aparece localizado en un ámbito territorial y resulta cotidiano; los ciudadanos buscan y exigen soluciones al municipio ${ }^{11}$. Son servicios y funciones muy visibles, sometidos a un control, presión y exigencia de los destinatarios. Si funcionan mal, la crítica y la desafección son inmediatas; si mejoran y responden adecuadamente a las demandas o expectativas, el reconocimiento también lo es.

- El gobierno local muestra una gran accesibilidad. En el desarrollo de las políticas públicas municipales, los ciudadanos y los grupos tiene más posibilidades de influir. Por el tamaño del «escenario» y por las relaciones que en él se dan, la política municipal es más permeable a los intereses sociales y a los requerimientos ciudadanos.

- Por su cercanía, el gobierno local actúa como agente de intermediación entre la sociedad y el sistema político en su conjunto; entre el sector público y privado; entre intereses de distintos niveles y entre gobiernos que mantienen competencias en su ámbito territorial. En este contexto, el gobierno local asume una función de

\footnotetext{
${ }^{11}$ Así ocurre actualmente en las grandes ciudades con los problemas que afectan a la seguridad ciudadana. Según datos de recientes encuestas de victimización-opinión en Valladolid, un 48\% de ciudadanos considera al Alcalde responsable de la seguridad en la Ciudad. Más del 75\% considera que, en todo caso, «debería serlo» para mejor solución del problema. Más allá de las atribuciones formales, ahora en proceso de modificación, las Políticas Municipales desarrollan amplias tareas en esta materia, a impulso de la proximidad.
} 
liderazgo, de dinamización y conducción del desarrollo social, de extraordinaria importancia.

Todo esto provoca una tendencia expansiva en las tareas y en los gastos, más allá de las competencias formales atribuidas (se calcula en un $30 \%$ las funciones «no propias» que desarrollan los municipios) que exige la pronta y efectiva aplicación del famoso principio de subsidiariedad, consagrado en la Carta Europea de la Autonomía Local: «el ejercicio de las competencias públicas debe, de modo general, incumbir preferentemente a las autoridades más cercanas a los ciudadanos. La atribución de una competencia a otra autoridad debe tener en cuenta la amplitud y la naturaleza de la tarea o las necesidades de eficacia o economía». La subsidiariedad no es sólo cuestión de proximidad, también de capacidad, de forma que las políticas las desarrolle la Administración que asegure mayor calidad: satisfacción a costes razonables. Los municipios están mejor situados para lograrlo, pero necesitan los medios, tanto económicos como estructurales, para poder hacerlo. Por ello resulta perentorio el desarrollo del Pacto Local o «segunda descentralización» ${ }^{12}$.

Los municipios, en atención al factor proximidad, son el escenario más propicio para fortalecer la participación del ciudadano corriente en las políticas públicas y para gestionar con sistemas efectivos de calidad.

\section{Liderazgo fuerte}

La Administración Municipal tiene en la figura del Alcalde un liderazgo fuerte y de fácil identificación. Se trata de un liderazgo «posicional» y por ello únicamente potencial, pero sumamente importante en relación con la calidad total y la legitimidad por rendimientos.

\footnotetext{
${ }^{12}$ El nuevo Proyecto de Ley «Medidas para la Modernización del Gobierno Local», recientemente aprobado por el Consejo de Ministros, incorpora en su Título X el contenido del llamado «Régimen de Grandes Ciudades». Se trata únicamente de un régimen orgánico-funcional. Los aspectos competenciales no se abordan; sin duda porque en su inmensa mayoría dependen de las Comunidades Autónomas. No obstante, la proposición no de ley, aprobada por el Congreso de los Diputados el 11 de marzo del año en curso, «Sobre las grandes ciudades y su área de influencia urbana», contiene un apartado 4. ${ }^{\circ}$ que propone: «Impulsar la transferencia de competencias a las Administraciones Locales en materia de vivienda, empleo, servicios y prestaciones sociales; educación y en las demás políticas de proximidad que así lo requieran, evitando la duplicidad de actuaciones de las diversas Administraciones Públicas y clarificando la distribución competencial. Las transferencias de competencias habrán de efectuarse de forma pactada entre la Administración transferente y la destinataria de las mismas, garantizándose en todo caso la suficiencia financiera para la adecuada prestación de los servicios correspondientes». Un claro «mandato», sustentado en el consenso político al máximo nivel, dirigido a las CC.AA. que deben realizar el proceso de descentralización. La racionalización de competencias no puede esperar mucho y la situación económica de los grandes municipios — pese a sus esfuerzos de eficiencia y calidad— tampoco.
} 
La posición fuerte del Alcalde deviene de su doble configuración constitucional y legal: por un lado, es Presidente de la Corporación y, por otro, un órgano en sí mismo, con funciones de dirección y ejecución. El Alcalde, como presidente de la Corporación, efectúa una representación político-institucional hacia el exterior que le dota de gran fuerza simbólica, contribuyendo a su identificación con la ciudad. Además, y en el plano orgánico, le confiere la presidencia de los órganos colegiados de la Entidad, especialmente el Pleno Municipal o Ayuntamiento, lo que fortalece su posición interna y externa. Como titular del órgano Alcaldía, destaca la técnica de concentración de atribuciones, acompañada de gran flexibilidad en las facultades de delegación. Esto le confiere una posición fuerte en términos de dirección política y del aparato administrativo. Esta doble configuración otorga una posición muy favorable para desarrollar un liderazgo, tanto externo (en el ámbito de la ciudad) como interno (en la propia Administración Municipal).

La configuración del subsistema político-administrativo local y el ordenamiento determinan un Alcalde fuerte en cuanto a su posición formal. El desarrollo de este liderazgo potencial y su efectividad dependen de dos factores igualmente importantes: las habilidades y comportamiento de la persona titular y las características del municipio, en cuanto «ámbito de dominio político». El liderazgo se define en un sentido amplio como forma especial de poder que ejerce un individuo sobre una amplia variedad de asuntos y personas. Es siempre un fenómeno relacional: no puede haber líder sin que haya seguidores. El liderazgo se desarrolla como proceso interactivo con tres elementos esenciales: el líder, el ámbito en el que actúa y la relación entre ambos. En el origen del proceso suele haber una posición formal de autoridad, aunque no es imprescindible. En el caso del Alcalde esa posición es fuerte y con mecanismos poderosos. El desarrollo depende de la relación Alcalde-Ciudad. Es importante que el Alcalde construya un discurso político «diferenciado» con el que la Ciudad se identifique. Pero también influye el talante personal; su protagonismo en las políticas públicas; el éxito de éstas; su peso específico en el ámbito del sistema político nacional; las redes de influencia y coaliciones que logre construir en torno a su persona; la duración en el cargo, etc.

El liderazgo del Alcalde tiene una gran importancia en el subsistema político-administrativo municipal:

- Contribuye poderosamente a dotar a la Entidad de una Visión y unas Estrategias; y sobre todo a comunicarlas e involucrar en ellas al entramado ciudadano. 
- Favorece el desarrollo de la cultura corporativa en la Administración Municipal.

- Facilita el dominio de la complejidad organizacional.

- Contribuye a identificar y encauzar las demandas e intereses vecinales.

- Impulsa fuertemente la gestión.

- Personificando la acción de gobierno y simplificando la política, contribuye a identificar a los ciudadanos con su gobierno municipal.

El liderazgo del Alcalde es un factor muy positivo a la hora de desarrollar un sistema de Gestión de Calidad Total. La innovación, los cambios culturales y los «compromisos» sólo son posibles a impulsos de un liderazgo fuerte que contribuya a vencer las inercias, las resistencias y la apatía. Un «compromiso» de servicio y de eficiencia, formulado por un Alcalde fuerte ante la ciudadanía, tiene un poderoso efecto movilizador.

A su vez, el Alcalde-líder necesita ofrecer a los ciudadanos rendimientos: calidad de vida, ciudad transformadora,... Y para ello necesitará gestionar bien, es decir, impulsar la calidad total como estrategia de dirección.

Liderazgo y calidad se precisan y complementan en el ámbito municipal. Ambas contribuyen, como veremos, al incremento de la legitimidad, en la medida en que concitan apoyos de la ciudadanía. De esos apoyos depende en buena medida el liderazgo consolidado y la continuidad del líder-regidor. Por todas estas conexiones, los liderazgos municipales fuertes y continuados suelen sustentarse, entre otros aspectos, sobre una gestión considerada «de calidad».

\section{Gobiernos Locales y legitimidad por «calidad»}

Decíamos antes que el motor que impulsa a las Administraciones Públicas en general a trabajar con Calidad es el afán de mantener o incrementar sus apoyos, de legitimarse en función de rendimientos, lo que afecta a la legitimidad del sistema político-administrativo en su conjunto. Esta afirmación, en el caso de la Administración Municipal, adquiere mayor importancia y perfiles propios. 
Se ha dicho que uno de los factores más destacados que presionan a favor de la modernización municipal es «la despolitización del voto local y el interés por vincular el voto político con la calidad y cantidad de los servicios públicos prestados ${ }^{13}$. Es una realidad constatada que el comportamiento electoral en las municipales se distingue cada vez más de otros procesos electorales y adquiere connotaciones distintas en cada ciudad. También lo es el hecho de que los apoyos que la ciudadanía otorga a la Administración Municipal tienen causas y manifestaciones propias con frecuencia alejada del típico comportamiento partidista. Pero ello no se debe a una despolitización sino a que lo municipal tiene su especificidad, su propia «imagen de marca» ante los ciudadanos. Como hemos visto, el gobierno municipal tiene una especificidad muy acentuada en relación al conjunto del sistema político. En España, a lo largo de la etapa democrática, los municipios han conseguido perfilar ante los ciudadanos una identidad, una «imagen de marca» propia, en general y concreta en cada ciudad. Esa imagen específica, que de su propio gobierno municipal tienen los vecinos, determina los apoyos que van otorgarle. En la configuración de la «imagen de marca» interviene «la política» como juego partidista, pero también y de forma relevante, otros factores: identidad y «proyecto» de Ciudad; transformaciones urbanas de gran calado, cantidad y calidad de servicios; rendimientos en el desarrollo de las políticas; dominio de la intergubernamentalidad, con la consiguiente atracción de recursos; personalidad y liderazgo del Alcalde... Todos ellos interrelacionados y en términos de percepción. En lo municipal, los datos objetivos y las percepciones suelen tener un alto grado de coincidencia, pero no siempre es así y nunca lo es en términos absolutos. Para la obtención y consolidación de apoyos, es más importante la percepción de los elementos citados que los datos objetivos en que se sustenten. Esto refuerza más aún el factor liderazgo del Alcalde, en cuanto a su capacidad para comunicar, transmitir e identificar a los ciudadanos con la Administración Municipal.

Así pues, la legitimidad en el ámbito municipal presenta una problemática específica:

- El peso de la legitimidad o rendimientos es mayor que en otros niveles de gobierno. En los niveles inferiores más desagregados o funcionalmente especializados del sistema, esto ocurre con carácter general. En el caso de los municipios se acentúa por su proximidad, receptividad y generalidad. La Administración Municipal

\footnotetext{
13 J. López Camps y A. Gadea Carrera, Servir al ciudadano. Gestión de Calidad en la Administración Pública. Ediciones Gestión 2000 S.A. e IVAP, Barcelona, 1995.
} 
gestiona el universo de intereses de los vecinos y desarrolla las funciones y servicios que más influyen en el día a día. Además se muestra más permeable a las demandas, menos distante y participativa. Por ello sufre más la presión, pero si los resultados son buenos, en percepción de los ciudadanos, también recibe más apoyos, en términos de opinión y de voto. En la interrelación entre las «políticas públicas» y el juego de «la política», pesan más las primeras. En consecuencia, tiene mayor alcance en la legitimidad una buena resolución de los problemas, en término de rendimiento.

- La personalidad y el liderazgo del Alcalde tienen una notable importancia en la captación y aseguramiento de los apoyos a la Administración Municipal. El liderazgo impulsa a la gestión y a la obtención de buenos rendimientos. Pero, además, suele tener su propia especificidad en términos de legitimidad. Hasta el punto de constituir «el tercer factor», junto a la legitimidad general y la de rendimientos.

- Hablando de legitimidad nunca podemos olvidar los valores. En el desarrollo de las políticas municipales, los vecinos esperan resultados pero también, y quizás con preferencia, un trato justo, un reparto equitativo de las prestaciones y de las cargas. A veces, es más importante participar y sentirse partícipe del resultado de las políticas, que el resultado en sí mismo. Una visión meramente cuantitativa de los rendimientos puede resultar profundamente errónea.

En la medida en que los conceptos de Calidad Total o Gestión Excelente tienen un carácter general, que incluye toda mejora en sentido amplio y no sólo de resultados; en la medida en que significan e implican la satisfacción de las aspiraciones y expectativas del ciudadano con carácter integral; tienen una conexión evidente con la legitimidad, más aún que los rendimientos en sentido estricto. Por ello podríamos hablar de una legitimidad «de calidad» en el ámbito municipal. Esa legitimidad de calidad; la percepción vecinal de que el gobierno municipal hace las cosas bien; contribuye fuertemente a mantener los apoyos, lo que explica la reiterada continuidad de algunos gobiernos municipales. Lo contrario disgrega y dispersa los apoyos. 


\section{ORIENTACIONES BÁSICAS PARA UNA GESTIÓN LOCAL DE CALIDAD}

Una Entidad Local que quiera gestionar con calidad deberá construir su propio sistema de dirección y gestión, basado en los fundamentos y técnicas de la calidad total. La calidad no se logra con actuaciones aisladas y menos aún con simples declaraciones propagandísticas. El cambio sólo resulta posible desde la acción global, planificada de forma abierta, pero integral.

El sistema tiene que fundamentarse en valores $y$ principios, que constituyen la base de una cultura corporativa de compromiso e innovación. Los contenidos y actuaciones son contingentes. Los principios deben ser sólidos, enraizados y compartidos por toda la organización. Entre los principios hay cuatro que no pueden faltar: legalidad, transparencia, responsabilidad y eficiencia. La defensa de las leyes, de los derechos del ciudadano y del interés general son el fundamento de cualquier proceso de calidad en la Administración Pública. La transparencia, la información detallada y fiable, así como el fomento de la participación ciudadana han de estar presentes en toda política pública municipal. Todos los gestores y empleados municipales son responsables ante los ciudadanos. Pensar e innovar es cosa de todos: las mejores soluciones surgen de la investigación, el esfuerzo y el compromiso. Obtener los mejores resultados posibles en el desarrollo de las funciones y en la prestación de los servicios ha de ser la máxima preocupación de los gestores municipales, en un contexto de austeridad y control del gasto.

El sistema de calidad municipal se construye pensando la ciudad y reorientando el gobierno en función de las personas. Un plan de Calidad Total tiene que dar respuesta a los retos que tenga planteado el gobierno, para transformar la ciudad, logrando mejor calidad de vida de los ciudadanos. Pensando en las personas, debemos dibujar la visión que de la ciudad tengamos a medio y largo plazo y diseñar las grandes líneas de actuación. Luego las concretaremos en iniciativas, tareas y proyectos de mejora de la gestión. Hablamos de estrategias, no necesariamente de un Plan Estratégico. No debe confundirse el fin con los instrumentos. Menos aún priorizar los nombres frente a los principios y los contenidos. Una ciudad puede aprobar un Plan Estratégico y desplegar un sistema de calidad. Otra se puede basar en un Plan de Innovación,... Tal como lo hemos expuesto, el concepto de Calidad Total es amplio y general, absolutamente integrador. Por ello debe partir de una visión estratégica y comprender desde los grandes proyectos hasta los pequeños detalles que generan calidad de vida. 
El sistema tiene que ser verdaderamente «propio», pensado por y para la Administración Municipal de que se trate. Cada ciudad tiene una problemática y cada gobierno local unos retos. Cada organización una estructura y una dinámica peculiares, que deben ser adecuadamente diagnosticadas. En el plano de las técnicas y herramientas, conviene un sistema mixto-ecléctico. No solo porque la tendencia general es a la convergencia de modelos, sino porque la complejidad de la organización municipal lo aconseja. Debe ser un sistema endógeno, a desarrollar en lo fundamental por personal interno. Calidad es gestión integral orientada a la mejora continua. Nadie externo puede «hacernos» la gestión. Un sistema que se desarrolle externalizado conduce a la existencia de «caminos paralelos». No servirá para mejorar realmente la organización.

El sistema tiene que ser tan ambicioso en sus objetivos, como sencillo y adaptado a la realidad en sus contenidos concretos. El desarrollo de un plan de calidad no puede absorber gran cantidad de recursos organizacionales. La Administración Municipal está muy pegada a la realidad y presionada. Es importante tener claro que no se puede parar el día a día para hacer calidad. También debe ser práctico y ofrecer pronto resultados tangibles. Este es un aspecto sumamente importante: el Plan tiene que combinar adecuadamente globalidad e integración, con practicidad y suma concreción. En los comienzos, debe aplicarse un «Plan piloto»; una experiencia singular de aplicación anticipada de los principios y contenidos del Plan en un sector de actuación elegido con sumo cuidado. Actuará como referente y generará confianza ${ }^{14}$.

El sistema de calidad tiene que desarrollarse desconcentrado; con un órgano central de impulso y coordinación, y con fuerte liderazgo político y gerencial. Cada servicio o centro gestor deberá implicarse en el desarrollo del sistema, a partir de una reflexión sobre sus «metas y objetivos», su adecuación organizativa, su comité de proyecto o grupo de mejora... y aplicar las herramientas más adecuadas conforme a las bases del Plan. El desarrollo del Plan no puede «imponerse» desde el núcleo central especializado, pues se corre el riesgo de que se perciba como una carga añadida. El compromiso con el cambio tiene que partir de las unidades gestores, a impulsos de un liderazgo fuerte, que como no puede ser de otra manera, corresponderá al Alcalde. El desarrollo tiene que apoyarse en

\footnotetext{
${ }^{14}$ En Valladolid, al tiempo que se aprueba, tras un largo proceso de preparación, el Plan de Mejora de la Calidad, a comienzos de 2000, se implantó el sistema de calidad en la Policía Municipal, con la obtención el día 8 de marzo de 2000 del Certificado de Calidad conforme a las normas UNE-EN-ISO 9002. Ver V. Merino y J. LóPEZ de Haro, «La Nueva Policía Municipal: estrategias, organización y calidad». REAL. n. ${ }^{\circ} 288$, Enero-abril, 2002, pp. 247 y ss.
} 
abundante información interna, formación y estímulos concretos a las iniciativas de los gestores y de todos los agentes implicados.

\section{A MODO DE CONCLUSIONES}

La Calidad Total, como paradigma actual de la gestión, hace referencia a una estrategia de dirección orientada al «cliente» y basada en el compromiso. Un concepto amplio, abierto y flexible, aplicable con carácter general a todas las organizaciones. $\mathrm{Al}$ aplicar los principios y técnicas de Calidad Total en la Administración Pública es preciso tener muy en consideración su especificidad como organización, en atención a la función central que desarrolla y al sistema de valores.

El motor que impulsa a las Administraciones Públicas a trabajar con calidad es el afán de sostener o incrementar su legitimidad.

En las Administraciones Locales la legitimidad por rendimientos tiene un mayor peso específico y connotaciones propias. Por ello y por determinadas características relacionadas con el tipo de funciones y con la posición que ocupan en el sistema político-administrativo, constituyen el ámbito idóneo para el desarrollo de sistemas de gestión de calidad. La aplicación de modelos de Calidad Total fortalece la posición del ciudadano corriente en el desarrollo y control de las políticas públicas e incrementa su participación. Por tanto, refuerza la dimensión democrática y la legitimidad general de los gobiernos locales.

Una Entidad Local que quiera gestionar con calidad debe construir su propio sistema de dirección y gestión, basado en los fundamentos y técnicas de la Calidad Total. El marco conceptual y las experiencias desarrolladas ofrecen un conjunto de orientaciones básicas, que nunca podrán sustituir al esfuerzo de reflexión y adaptación para configurar un «modelo» propio. 